\title{
Patient-Reported Symptom Severity in a Nationwide Myasthenia Gravis Cohort
}

\section{Cross-sectional Analysis of the Swedish GEMG Study}

Malin Petersson, MD, Amalia Feresiadou, MD, Daniel Jons, MD, Andreea llinca, MD, PhD, Fredrik Lundin, MD, PhD, Rune Johansson, MD, Anna Budzianowska, MD, Anna-Karin Roos, MD, Viktor Kågström, MD, Martin Gunnarsson, MD, PhD, Peter Sundström, MD, PhD, Fredrik Piehl, MD, PhD, and Susanna Brauner, MD, PhD

Neurology ${ }^{\circledR}$ 2021;97:e1382-e1391. doi:10.1212/WNL.0000000000012604

\section{Abstract}

\section{Background and Objectives}

To describe myasthenia gravis activities of daily living (MG-ADL) in relation to clinical characteristics in a large Swedish nationwide cohort.

\section{Methods}

In a cross-sectional prevalence cohort study, the Genes and Environment in Myasthenia Gravis study, performed from November 2018 through August 2019, patients with myasthenia gravis (MG) were invited to submit an extensive 106-item life environment questionnaire, including the MG-ADL score. Patients were classified into early-onset MG (EOMG, <50 years), lateonset MG (LOMG, $\geq 50$ years), or thymoma-associated MG (TAMG). Comparisons of disease-specific characteristics were made between subgroups, sexes, and different MG-ADL scores.

\section{Results}

A total of 1,077 patients were included, yielding a 74\% response rate: 505 (47\%) were classified as EOMG, 520 (48\%) LOMG, and 45 (4\%) TAMG. Mean age at inclusion was 64.3 years (SD 15.7 ) and mean disease duration was 14.6 years (SD 14.0). Complete MG-ADL scores ( $\mathrm{n}=$ 1,035 ) ranged from $0 \mathrm{p}$ to $18 \mathrm{p}$, where $26 \%$ reported a score of $0 \mathrm{p}$. Higher MG-ADL scores were associated with female sex, obesity, and diagnostic delay (odds ratio [OR] 1.62, 1.72, and 1.69; $p_{\text {adj }}=0.017,0.013$, and 0.008$)$ and inversely correlated with high educational attainment (OR $0.59 ; p_{\text {adj }}=0.02$ ), but not with age at inclusion, disease subtype, or disease duration. Almost half of the population ( $47 \%$ ) reported MG-ADL $\geq 3 \mathrm{p}$, corresponding to an unsatisfactory symptom state.

\section{Discussion}

In this nationwide study, comprising more than $40 \%$ of the prevalent MG population in Sweden, almost half of the patients reported current disease symptoms associated with an unsatisfactory symptom state, indicating the need for improved treatment options.

\section{Correspondence}

Dr. Brauner

susanna.brauner@ki.se

\section{RELATED ARTICLE}

Editorial

People With Myasthenia

Are Getting Better, but Are

They Doing Well?

Page 663 


\section{Glossary}

AIC = Akaike information criterion; $\mathbf{C I}=$ confidence interval; EOMG = early-onset myasthenia gravis; ePASS = estimated patient acceptable symptom state; GEMG = Genes and Environment in Myasthenia Gravis; ICC = intraclass coefficient; ICD = International Classification of Disease; LOMG = late-onset myasthenia gravis; $\mathbf{M G}=$ myasthenia gravis; $\mathbf{M G - A D L ~ = ~}$ myasthenia gravis activities of daily living; $\mathbf{M G r e g}=$ national clinical MG registry; OR = odds ratio; PASS = patient acceptable symptom state; PROM = patient-reported outcome measure; TAMG = thymoma-associated myasthenia gravis.

Myasthenia gravis (MG) is an autoantibody-mediated neuroinflammatory disease characterized by fluctuating muscle weakness and muscular fatigability. ${ }^{1,2}$ Clinical management has evolved considerably during the past century, ${ }^{3}$ but MG still causes serious morbidity and a substantial effect on patients' quality of life. ${ }^{4}$ Patient-reported outcome measures (PROMs) are gaining increasing attention, both for MG and other chronic inflammatory diseases. ${ }^{5}$ MG-specific PROMs, such as MG activities of daily living (MG-ADL), ${ }^{6}$ more readily reflect the disease activity over time compared to point-in-time evaluations, ${ }^{7}$ which is particularly important in a disease like MG, given its known fluctuation during the day. MG-ADL correlates well to several other MG outcome measures such as the quantitative myasthenia gravis score, MG composite, as well as the MG 15-item Quality of Life Scale. ${ }^{7,8}$ PROMs are estimated by the patient independently and have been increasingly used in clinical trials. ${ }^{9-12}$

The prevalence of MG in Sweden was estimated to be 24.8/ 100,000 in $2010 .^{13}$ Prevalence has increased dramatically in the past century. The incidence has also increased in past decades, especially in the late-onset group., ${ }^{3,14}$ The Genes and Environment in Myasthenia Gravis (GEMG) study was launched in order to provide improved information on causative factors and disease characteristics in a large nationwide cohort.

The main objective of the present study was to describe the basic and disease-specific characteristics of the GEMG study cohort in relation to symptom severity as reflected by the MGADL scale.

\section{Methods}

\section{Study Population}

The GEMG study is a Swedish nationwide cross-sectional study of patients with MG. We invited all patients registered in the national clinical MG registry (MGreg $[\mathrm{n}=724]$; neuroreg.org), patients who contacted the study upon learning about it from the patient organization $(\mathrm{n}=56)$, and all additional patients who had received the ICD code for MG (G70.0) upon clinical visits on at least 2 occasions during 2010 through 2018 at 12 collaborating hospitals including all Swedish university hospitals $(\mathrm{n}=847)$ (Figure 1). MGreg was initiated in 2011 as a nationwide publicly funded quality registry to collect information on disease course and longterm outcomes with MG prospectively but remains a voluntary option for patients and participating centers. Of the 56 patients who contacted the study through the patient organization, $39(70 \%)$ were later identified via collaborating hospitals. A total of 1,627 invitations were sent out. All patients with MG diagnosis aged 18 years or older at study start were included. Exclusion criteria were insufficient Swedish reading proficiency or disease onset $<13$ years of age, to avoid inclusion of patients with congenital myasthenic syndrome. All residents in Sweden have a unique personal identification number composed of their date of birth and 4 additional digits. Participating patients were identified using the personal identification number and duplicates of patients who were contacted twice by mistake were removed $(\mathrm{n}=12)$. Recruitment and data collection were carried out from November 2018 to July 2019. Supplementary telephone interviews were made after reviewing all questionnaires and data lock was on August 31, 2019.

\section{Data Collection}

Patients were invited to participate by responding to an extensive and standardized online or paper questionnaire regarding historic and present environmental and lifestyle exposures as well as disease-specific questions. ${ }^{19-21}$ Patients were asked to participate by responding to an online or paper questionnaire. Patients fulfilling inclusion criteria were contacted up to 4 times.

Paper questionnaires were received from 452 patients, 624 patients filled in the web-based version, and 1 patient was interviewed by telephone due to severe visual impairment. Patients submitting a paper questionnaire were older (69.3 [SD 14.1] vs 60.7 [SD 15.8] years; $p<0.001)$ and more likely to have late-onset MG (LOMG) subtype ( $57 \%$ vs $46 \%$; $p<$ $0.001)$.

Paper questionnaires were registered manually into the same database as the web-based responses, providing the full data set for further analyses.

\section{Outcome Variables}

Patients reporting ever having a thymoma were classified into thymoma-associated MG (TAMG) and remaining patients were stratified by age at disease onset: $<50$ years (early-onset MG [EOMG]) and $\geq 50$ years (LOMG). Thirty-two patients did not remember the year of onset. Of these, 25 were classified based on year of onset or diagnosis reported in MGreg $(\mathrm{n}=10)$, anamnestic information on decade $(\mathrm{n}=1)$, or approximate year of diagnosis $(n=14)$; the remaining 7 patients were not subgrouped. 

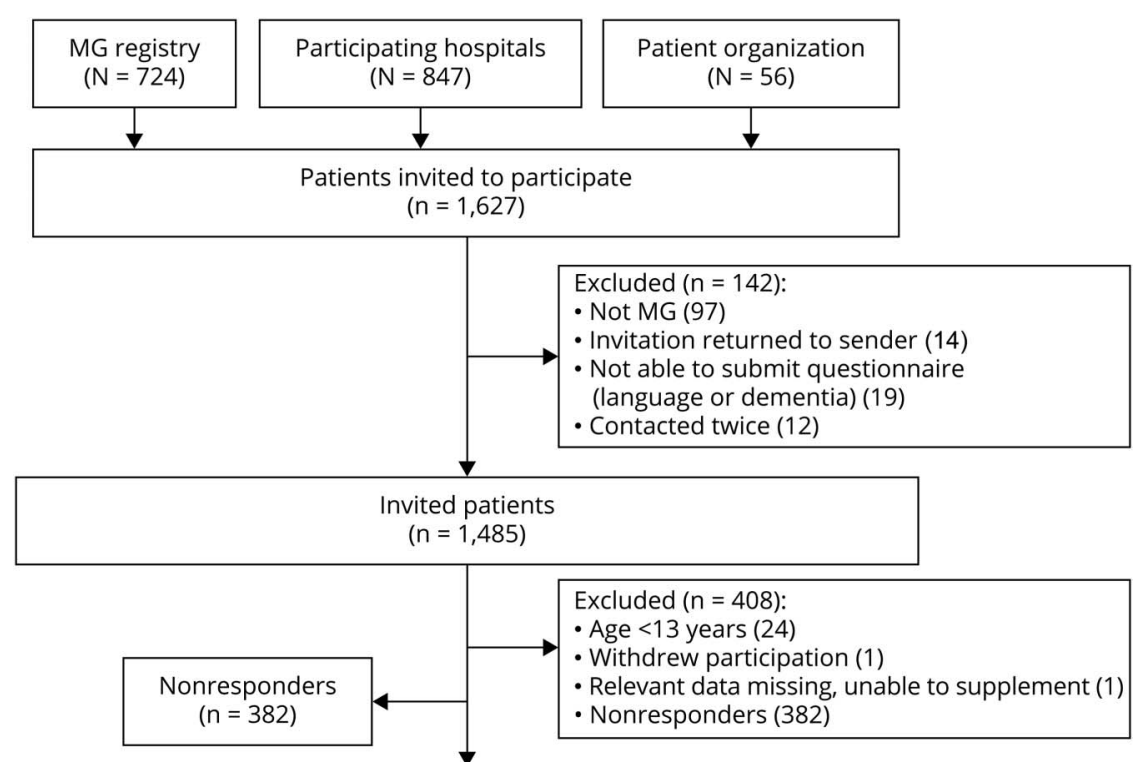

Study population $(\mathrm{n}=1,077)$

( $74 \%$ of 1,459 patients met inclusion criteria and did not fulfill exclusion criteria)
GEMG = Genes and Environment in Myasthenia Gravis study; MG = myasthenia gravis.
Patients were asked to report symptoms at onset, at peak of disease, and at study inclusion. A patient was deemed as having generalized disease if ever reporting generalized symptoms at any of the above mentioned timepoints.

All participants were asked to report an itemized MG-ADL score, which was subsequently used to estimate patient acceptable symptom state (PASS). ${ }^{9}$ PASS is a 1 -questionbased score that has been validated in multiple chronic inflammatory diseases including $\mathrm{MG}^{22,23}$ Patients respond to the question "Considering all the ways you are affected by myasthenia, if you had to stay in your current state for the next months, would you say that your current disease state status is satisfactory?" The cutoff for a satisfactory state in MG has previously been reported at $2 p$ in MG-ADL. ${ }^{9}$ We therefore used this cutoff to make an estimated PASS (ePASS). An unsatisfactory symptom state, MG-ADL $\geq 3 \mathrm{p}$, is termed negative ePASS, and a satisfactory symptom state, $\mathrm{MG}-\mathrm{ADL} 0 \mathrm{p}-2 \mathrm{p}$, is termed positive ePASS.

\section{Statistics}

All statistical analyses were performed using $\mathrm{R}$ version $4.0 .3^{24}$ and RStudio version 1.3.1093. Statistical significance was defined as $p$ value $<0.05$. Means and SD were calculated for continuous variables and counts and frequencies for categorical variables. Differences in continuous variables were assessed by Wilcoxon rank sum test, categorical variables with all groups of $\mathrm{n} \geq 5$ were assessed by $\chi^{2}$ test, and Fisher exact test was used for categorical variables with any group of $\mathrm{n}<5$. Adjusted $p$ values and odds ratios (ORs) or $\beta$ values with $95 \%$ confidence interval (CI) were obtained by multivariate regression models with the dependent variable as continuous MG-ADL or MG-ADL dichotomized into $0 \mathrm{p}-5 \mathrm{p}$ (approximation of no severe generalized disease) or $\geq 6 p$ with at least $1 p$ in nonocular items (approximation of severe generalized disease). Patients with $6 p$ in only ocular items $(n=5)$ were put into the $0 \mathrm{p}-5 \mathrm{p}$ category. Categorical independent explanatory variables were sex (female or male), subgroup (EOMG, LOMG, or TAMG), diagnostic delay $\geq 2$ years (yes or no), current tobacco use (yes or no), current coffee consumption (yes or no), body mass index $(<25$, overweight or obese), and university degree (yes or no). Continuous independent explanatory variables were disease duration in years from onset and age at inclusion in years. Model fit statistics were used to calculate Akaike information criterion (AIC) values for both models; linear model (AIC $=4,997)$ and multivariate regression model $(\mathrm{AIC}=898)$ and data from the multivariate model are therefore presented. Due to the exploratory nature of the study, no correction for multiple testing was performed.

\section{Quality Control}

Internal validation of the manual registration of data from paper questionnaires was performed by one of the authors (M.P.) in order to assess potential bias and errors at data entry. Forty-nine randomly chosen paper questionnaires (approximately 10\%) were reimputed into the web module. Interrater agreement was determined for each variable by calculating the Cohen kappa. The mean Cohen kappa for all variables was 0.93 . Values $>0.80$ are considered strong. ${ }^{25}$ 
External validation was performed to assess potential recall bias. The magnitude of recall bias was estimated by comparing patient-reported data on time of disease onset, diagnosis, and thymectomy against data recorded in MGreg. Mean deviation (patient reported - physician reported), SDs, and intraclass coefficient (ICC) assessing 1-way consistency among data were calculated. The mean deviation was $<1$ year for disease onset, diagnosis, and thymectomy. ICCs were $0.93,0.96$, and 0.97 , respectively. ICC values of $0.75-0.90$ indicate good reliability and values $>0.90$ excellent reliability. ${ }^{26}$ Potential association between disease duration and difference in selfreported data and data in MGreg was also investigated by calculating the Spearman correlation coefficient for disease onset $(R=0.27, p=1.3 \mathrm{e}-07)$, diagnosis $(R=0.29, p=1 \mathrm{e}-08)$, and thymectomy $(R=0.26, p=0.0084)$.

To further assure the representability of the cohort, a nonresponder analysis was carried out by comparing age, sex, and region of residence for responders and nonresponders.

\section{Standard Protocol Approvals, Registrations, and Patient Consents}

The study was approved by the Regional Ethics Committee Stockholm, Sweden (2018/1,436-31) and all participating patients gave written informed consent. The study was conducted in accordance with the Strengthening the Reporting of Observational Studies in Epidemiology (STROBE) guidelines.

\section{Data Availability}

Deidentified data relating to the study are available from the corresponding author upon reasonable request and ethics approval.

\section{Results}

The final study population comprised 1,077 individuals of 1,459 invited eligible participants, resulting in a $74 \%$ response rate (Figure 1). We estimate that the cohort covers $42 \%$ of all patients with MG in Sweden, based on a recent prevalence estimate obtained through compulsory national health registries and the population size as of December 31, 2019. ${ }^{13,27}$ Nonresponders were younger (61.4 years [SD 18.3]) compared to responders (63.8 years [SD 16.0]) $(p=0.040)$. Internal and external validation assessing data entry and comparing patient to physician-reported data using MGreg displayed very strong agreement, indicating high accuracy of the dataset. A potential, but weak, correlation between disease duration and magnitude of difference in patient and physician-reported data was observed.

Mean age at diagnosis was 49.6 years (SD 20.1) and at inclusion 64.3 years (SD 15.7); 53\% of respondents were female (Table 1). Forty-five patients (4\%) reported a thymoma and were classified as TAMG and the remaining as EOMG ( $\mathrm{n}=$ $505)$ or LOMG $(n=520)$. Age at diagnosis stratified by sex revealed a bimodal incidence peak in female patients, whereas male patients were predominantly diagnosed at 70 years of age (Figure 2). The EOMG group was dominated by female patients (76\%), contrasting with the LOMG group (30\%; $p<0.001)$. As expected, patients with EOMG had undergone thymectomy to a higher extent (74\%) compared to LOMG (19\%; $p<0.001)$. Patients with EOMG more often reported generalized symptoms at onset (50\%), and LOMG, ocular symptoms (55\%) $(p<$ $0.001)$. At study inclusion, $30 \%$ reported no symptoms, and frequencies were similar in all subgroups (Table 1). Sexstratified analyses revealed significant differences in the EOMG subgroup (Table 2). Female patients with EOMG reported onset at a significantly earlier age (27.6 years [SD 9.4]) compared to men with EOMG (33.4 [SD 10.8]; $p<$ $0.001)$. Significantly more women with EOMG reported generalized symptoms at onset (55\% vs 37\%; $p<0.001)$ or ever (92\% vs $74 \%$ in men with EOMG; $p<0.001$ ).

Disease activity was assessed by the MG-ADL scale ${ }^{6}$ and scores ranged between $0 \mathrm{p}$ and $18 \mathrm{p}$ (Figure 3A, Table 1). A large proportion reported $0 \mathrm{p}(26 \%)$ and similar fractions of patients with no $(0 p)$, mild $(1 p-2 p)$, or moderate disease activity $(3 p-5 p)$ or severe generalized disease $(\geq 6 p)$ were observed between the subgroups (Figure $3 \mathrm{~B}$ ). Using a multivariate regression model, comparing patients with severe generalized disease to those without minimal manifestations, we sought to identify factors correlating with higher MG-ADL score (Table 3). We observed that female sex (OR 1.62; 1.09-2.41; $p_{a d j}=0.017$ ), obesity (OR 1.72; $\left.1.12-2.64 ; p_{a d j}=0.013\right)$, and diagnostic delay $\geq 2$ years $(\mathrm{OR}$ $\left.1.69 ; 1.14-2.48 ; p_{a d j}=0.008\right)$ significantly correlated with high disease activity. Having obtained a university degree (OR 0.59; 0.37-0.91; $p_{a d j}=0.02$ ) was inversely correlated with severe generalized disease. These correlations were also significant in a linear model including all patients (data not shown). In a subanalysis assessing the effect of thymectomy, neither thymectomy nor time to thymectomy was associated with $\mathrm{MG}-\mathrm{ADL}$, even when restricting the analyses to patients with EOMG (data not shown; $p_{a d j}$ $>0.1$ ).

We thereafter derived ePASS, a measure of patient-acceptable disease burden based on patient-reported MG-ADL (Table 1). MG-ADL scores of $\geq 3 p$ (i.e., ePASS negative) were reported by $47 \%$, indicating dissatisfaction with their current disease status. ${ }^{9}$ Patients with $\mathrm{MG}-\mathrm{ADL} \geq 3 \mathrm{p}$ at study inclusion more often had general symptoms at onset compared to patients with MG-ADL $0 \mathrm{p}-2 \mathrm{p}$ (44\% vs $37 \%$; $p=$ $0.019)$ and more reported ever having generalized symptoms ( $83 \%$ vs $73 \%$; $p<0.001)$. Among patients who were diagnosed within 2 years prior to study inclusion, fewer reported $M G-A D L ~ 0 p-2 p(37 \%)$, compared to patients diagnosed earlier $(55 \% ; p<0.001)$ (Figure 3C). This difference remained significant after adjustment for subgroup and age (OR 2.17; 1.40-3.41; $p_{a d j}<0.001$ ). 
Table 1 Comparison of Clinical Features Within Myasthenia Gravis (MG) Subgroups Early-Onset MG (EOMG), Late-Onset MG (LOMG), and Thymoma-Associated MG (TAMG)

\begin{tabular}{|c|c|c|c|c|c|c|c|c|}
\hline & $\mathbf{N}$ & Total & EOMG $(n=505)$ & LOMG $(n=520)$ & $p$ Value & Non-TAMG $(n=1,032)$ & TAMG $(n=45)$ & $p$ Value \\
\hline Female & 1,077 & $567(53)$ & $383(76)$ & $155(30)$ & $<0.001^{\mathrm{a}}$ & $539(52)$ & $28(62)$ & 0.2 \\
\hline Age at onset, y & 1,054 & $47.7 \pm 20.6$ & $29.0 \pm 10.1$ & $66.1 \pm 8.4$ & $<0.001^{a}$ & $47.6 \pm 20.7$ & $49.6 \pm 18.1$ & 0.5 \\
\hline Age at inclusion, $y$ & 1,077 & $64.3 \pm 15.7$ & $54.2 \pm 15.3$ & $74.1 \pm 8.3$ & $<0.001^{a}$ & $64.4 \pm 15.8$ & $62.6 \pm 13.9$ & 0.2 \\
\hline Disease duration (since onset), y & 1,054 & $16.4 \pm 14.8$ & $25.2 \pm 16.0$ & $7.8 \pm 6.0$ & $<0.001^{a}$ & $16.5 \pm 14.9$ & $13.0 \pm 12.7$ & 0.10 \\
\hline Diagnostic delay, y & 1,040 & $1.7 \pm 4.1$ & $2.6 \pm 5.4$ & $0.9 \pm 1.9$ & $<0.001^{a}$ & $1.8 \pm 4.1$ & $1.1 \pm 2.9$ & 0.076 \\
\hline Thymectomy & 1,064 & $514(48)$ & $370(74)$ & $99(19)$ & $<0.001^{a}$ & $470(46)$ & $44(98)$ & $<0.001^{\mathrm{a}}$ \\
\hline Symptom at onset & 1,062 & & & & $<0.001^{a}$ & & & $0.030^{\mathrm{a}}$ \\
\hline Ocular & & $482(45)$ & 187 (37) & $280(55)$ & & $470(46)$ & $12(27)$ & \\
\hline Bulbar & & $146(14)$ & $64(13)$ & $74(15)$ & & $139(14)$ & $7(16)$ & \\
\hline General & & $434(41)$ & $253(50)$ & $153(30)$ & & $408(40)$ & $26(58)$ & \\
\hline Disease progression & 1,048 & & & & $<0.001^{a}$ & & & 0.065 \\
\hline No generalization & & $236(23)$ & $62(12)$ & $165(33)$ & & $230(23)$ & $6(13)$ & \\
\hline Generalized at onset & & $434(41)$ & $253(51)$ & $153(31)$ & & $408(41)$ & $26(58)$ & \\
\hline Progression to generalized & & $378(36)$ & $184(37)$ & $181(36)$ & & $365(36)$ & $13(29)$ & \\
\hline Symptom at peak of disease & 1,054 & & & & $<0.001^{a}$ & & & 0.13 \\
\hline Ocular & & $238(23)$ & $79(16)$ & $151(30)$ & & $233(23)$ & $5(11)$ & \\
\hline Bulbar & & $87(8.3)$ & $15(3.0)$ & $68(14)$ & & $84(8.3)$ & $3(6.7)$ & \\
\hline General & & $729(69)$ & $406(81)$ & $284(56)$ & & $692(69)$ & $37(82)$ & \\
\hline Time from onset to peak of disease, $y$ & 991 & $2.8 \pm 5.6$ & $4.1 \pm 7.1$ & $1.6 \pm 3.3$ & $<0.001^{\mathrm{a}}$ & $2.8 \pm 5.6$ & $1.8 \pm 3.7$ & 0.12 \\
\hline Symptom at inclusion & 1,043 & & & & $<0.001^{a}$ & & & 0.064 \\
\hline No symptoms & & $310(30)$ & $138(28)$ & $158(32)$ & & $300(30)$ & $10(22)$ & \\
\hline Ocular & & $174(17)$ & $77(15)$ & $92(19)$ & & $170(17)$ & $4(8.9)$ & \\
\hline Bulbar & & $62(5.9)$ & $18(3.6)$ & $38(7.7)$ & & $56(5.6)$ & $6(13)$ & \\
\hline General & & $497(48)$ & $266(53)$ & $205(42)$ & & $472(47)$ & $25(56)$ & \\
\hline MG-ADL, p & 1,035 & $3.0 \pm 3.0$ & $2.9 \pm 3.1$ & $3.0 \pm 2.9$ & 0.2 & $3.0 \pm 3.0$ & $2.6 \pm 2.9$ & 0.4 \\
\hline ePASS & 1,035 & $552(53)$ & $265(54)$ & $257(52)$ & 0.5 & $526(53)$ & $26(60)$ & 0.3 \\
\hline
\end{tabular}

Abbreviations: ePASS = estimated patient acceptable symptom state; MG-ADL = Myasthenia Gravis Activities of Daily Living.

Data displayed as count (\%) or mean \pm SD. Data stratified by subgroups. $p$ Values for EOMG vs LOMG and for non-TAMG vs TAMG. For 7 patients (0.7\%), relevant information for subgrouping was missing and these patients were excluded from subsequent subgroup analyses.

a Significant.

\section{Discussion}

We report disease characteristics and patient-reported symptom state in a large nationwide prevalence MG cohort. The study had $74 \%$ response rate and is estimated to include $42 \%$ of all prevalent MG cases in Sweden, based on an epidemiologic study using compulsory national health registry data. ${ }^{13}$ Our major findings include a detailed characterization of disease activity based on MG-ADL, where increased score associated with female sex and overweight and inversely correlated to university education. We also estimate that, using an MG-ADL-based cutoff, almost half of the study population has an unsatisfactory symptom state. Lastly, we observe that women with EOMG display distinct clinical features, in contrast to men with EOMG, who are more like patients with LOMG of both sexes.

A majority of patients in our study $(\mathrm{n}=1,035)$ provided a complete MG-ADL score at inclusion. The score was used to investigate potential determinants of high disease activity and also to estimate PASS. For ePASS, we used the suggested cutoff by Mendoza et al. ${ }^{9}$ and stratified between patients 
Figure 2 Age and Sex

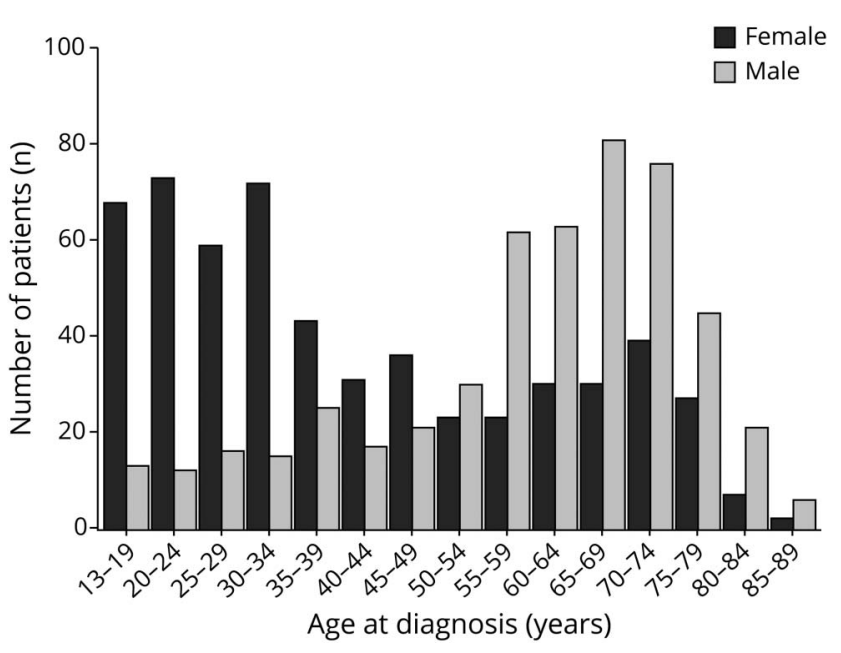

Age at diagnosis stratified by sex for all patients who reported a year of diagnosis $(n=1,066)$.

estimated to have achieved a satisfactory symptom state (MG$\mathrm{ADL} 0 \mathrm{p}-2 \mathrm{p})$ and those who had not (MG-ADL $\geq 3 \mathrm{p})$. Interestingly, a higher frequency of patients diagnosed less than 2 years prior to inclusion reported inadequate ePASS compared to those with longer disease duration. This might be explained by delayed onset of treatment effect, the natural course of the disease, or that patients get used to living with MG. ${ }^{28}$ Taken together, our findings underscore a need to improve treatment algorithms and develop more effective disease-modulatory drugs.

In a multivariate analysis, we observed that sex, obesity, diagnostic delay, and university education were significantly associated to MG-ADL score. In a recently published study investigating predictors for relapse in $\mathrm{MG}$, female sex was identified as a predictive variable for both relapse and reporting lower quality of life. ${ }^{29,30}$ Furthermore, severe disease was associated with low educational attainment and disability pension in a Norwegian study. ${ }^{31}$ The protective effect of a university degree could potentially be associated with increased health care seeking behavior and thereby a more well-treated and stable disease; this was not investigated in the present study. Disease subtype, disease duration, age at study inclusion, or tobacco use were not correlated with MG$\mathrm{ADL}$ score in our study.

A large proportion (40\%-85\%) of patients with MG present with ocular symptoms but within 2 years approximately $60 \%$ of these are reported to have developed generalized symptoms. $^{3,32,33}$ We were not able to estimate time to generalization, but we collected information on when patients experienced peak of disease and with what type of symptoms, and thereafter related it to time of onset. The average time from onset to peak of disease with generalized symptoms (3.0 [SD 5.7] years) is longer than previously reported time to generalization. However, some patients report peak of disease more than 5-10 years after diagnosis, which highlights the importance of continuous follow-up of this condition.

Autoimmune diseases are more common among women in general. In $\mathrm{MG}$, female patients more often develop disease in fertile age, but male patients primarily develop disease at older ages. In our study, we identified striking differences between female and male patients in the EOMG group. Female patients presented with generalized symptoms to a larger extent and developed generalized disease to a much higher degree than both male patients with EOMG and patients with LOMG of both sexes. Female patients with EOMG developed disease at significantly lower age compared to their male counterparts. Female patients with EOMG seem to be a clinically distinct entity whereas male patients with EOMG display characteristics more similar to patients with LOMG. There is no validated environmental risk factor to develop LOMG or EOMG in male patients, whereas sex hormones have been hypothesized to contribute to triggering of EOMG in female patients. ${ }^{34}$ On the basis of shared clinical characteristics, it may be speculated that the pathogenetic mechanism of EOMG in male patients is similar to LOMG, or that the male EOMG group to a larger extent is composed also of individuals with LOMG onset before 50 years of age. Improved biomarkers identifying the 2 subsets could allow for an improved disease stratification in the future, which might be of relevance when selecting therapeutic options such as thymectomy.

The frequency of thymoma in this cohort, $4 \%$, is lower than the $10 \%-15 \%$ reported in previous studies. ${ }^{35}$ This could possibly be a result of self-reported data due to recall bias or that patients have not been adequately informed. However, the frequency of TAMG in our cohort is in line with a recently published study using Swedish mandatory national registries, indicating an increased prevalence of nonthymomatous MG compared to previous cohort-based studies. $^{36}$ Other clinical features are in agreement with previously reported data regarding clinical presentation, age, and sex distributions. ${ }^{17,18,33}$ We performed both internal and external validation to identify potential bias in the cohort. In our validation of reported disease onset, diagnosis, and year of thymectomy, we observed that approximately $5 \%-10 \%$ of answers were not completely overlapping with physician-reported data. However, most answers differed by less than 2 years, indicating a lesser risk of severe recall bias. Because MG is a chronic disease, a larger proportion of patients with EOMG will have had the disease for a longer time and thereby have an increased risk of recall bias. However, in our analysis, disease duration displayed only weak correlation to incorrectly reported data.

This study has some important limitations. First, the reported cohort is estimated to comprise $42 \%$ of all patients diagnosed 
Table 2 Comparison of Clinical Features for Male and Female Patients Within Early-Onset Myasthenia Gravis (EOMG) and Late-Onset Myasthenia Gravis (LOMG) Groups

\begin{tabular}{|c|c|c|c|c|c|c|}
\hline & \multicolumn{3}{|l|}{ EOMG } & \multicolumn{3}{|l|}{ LOMG } \\
\hline & Female $(n=383)$ & Male $(n=122)$ & $p$ Value & Female $(n=155)$ & Male $(n=365)$ & $p$ Value \\
\hline Age at onset, y & $27.6 \pm 9.4$ & $33.4 \pm 10.8$ & $<0.001^{a}$ & $65.7 \pm 8.5$ & $66.2 \pm 8.4$ & 0.7 \\
\hline Age at inclusion, $y$ & $54.0 \pm 15.7$ & $55.1 \pm 13.9$ & 0.5 & $74.2 \pm 8.8$ & $74.0 \pm 8.2$ & 0.9 \\
\hline Disease duration (onset), y & $26.3 \pm 16.0$ & $21.7 \pm 15.7$ & $0.005^{\mathrm{a}}$ & $8.3 \pm 6.6$ & $7.6 \pm 5.8$ & 0.4 \\
\hline Diagnostic delay, y & $2.6 \pm 4.9$ & $2.7 \pm 6.6$ & $0.041^{\mathrm{a}}$ & $1.1 \pm 2.0$ & $0.8 \pm 1.9$ & 0.078 \\
\hline Thymectomy & $291(76)$ & $79(65)$ & $0.018^{\mathrm{a}}$ & $32(21)$ & $67(19)$ & 0.5 \\
\hline Symptom at onset & & & $<0.001^{\mathrm{a}}$ & & & 0.9 \\
\hline Ocular & $122(32)$ & $65(53)$ & & $79(53)$ & $201(56)$ & \\
\hline Bulbar & $52(14)$ & $12(9.8)$ & & $23(16)$ & $51(14)$ & \\
\hline General & $208(54)$ & $45(37)$ & & $46(31)$ & $107(30)$ & \\
\hline Disease progression & & & $<0.001^{a}$ & & & $>0.9$ \\
\hline No generalization & $31(8.2)$ & $31(26)$ & & $47(32)$ & $118(34)$ & \\
\hline Generalized at onset & $208(55)$ & $45(37)$ & & $46(31)$ & $107(30)$ & \\
\hline Progression to generalized & $139(37)$ & $45(37)$ & & $54(37)$ & $127(36)$ & \\
\hline Symptom at inclusion & & & $0.010^{\mathrm{a}}$ & & & 0.072 \\
\hline No symptoms & $103(27)$ & $35(29)$ & & $38(26)$ & $120(34)$ & \\
\hline Ocular & $47(12)$ & $30(25)$ & & $31(21)$ & $61(18)$ & \\
\hline Bulbar & $15(4.0)$ & $3(2.5)$ & & $7(4.8)$ & $31(8.9)$ & \\
\hline General & $212(56)$ & $54(44)$ & & $69(48)$ & $136(39)$ & \\
\hline MG-ADL, p & $3.0 \pm 3.1$ & $2.7 \pm 3.1$ & 0.2 & $3.4 \pm 3.0$ & $2.9 \pm 2.9$ & 0.087 \\
\hline ePASS & $193(52)$ & $72(60)$ & 0.2 & $67(46)$ & $190(54)$ & 0.082 \\
\hline
\end{tabular}

Abbreviations: ePASS = estimated patient acceptable symptom state; MG-ADL = Myasthenia Gravis Activities of Daily Living.

Data displayed as count (\%) or mean \pm SD. Data stratified by EOMG and LOMG and substratified by sex. $p$ Values for male vs female patients within EOMG and for male vs female patients within LOMG.

a Significant.

with MG in Sweden and may therefore be subject to selection bias. We were able to invite approximately $60 \%$ of the predicted prevalent MG population in Sweden, in relation to an epidemiologic study identifying all individuals receiving an MG ICD code diagnosis in specialized inpatient or outpatient care in 2005-2010. Here, patients were identified through a noncompulsory clinical MG registry, local medical records databases, and the national patient organization. Our method likely results in an enrichment of individuals with severe disease or ongoing immunomodulation requiring more frequent contact with health care, which may overestimate the proportion of patients with unsatisfying symptom states. However, the mean MG-ADL of the cohort is lower than in previous studies, which potentially indicates a more unbiased cohort. $^{30,37}$ Also, diagnostic specificity is likely higher compared to the use of ICD code registries. This notion is supported by the fact that we had to exclude 97 individuals not having MG out of 847 identified in participating hospital registries, after patients contacted us directly or review of medical records of patients from the Stockholm region. Second, as the study is based on patient-reported data, we were not able to obtain serologic information and could thereby only subdivide the cohort based on anamnestic information on presence of thymoma or reported disease onset. Still, in the subgroup of patients identified through the MGreg, prospectively collected physician-reported data showed a high level of agreement with patient-derived information. Third, ePASS was indirectly derived from MG-ADL by calculating the relation between these measures in other reported cohorts. Given the possible existence of differences in cohort structure across studies not accounted for, the calculated outcomes should be interpreted with caution. In addition, MG-ADL is subject to high floor effects and it is possible that patients with MG-associated symptoms exist in the group with $0 \mathrm{p} .{ }^{38}$ Lastly, we have not been able to take into account prescribed treatments for the calculated outcomes, such as 

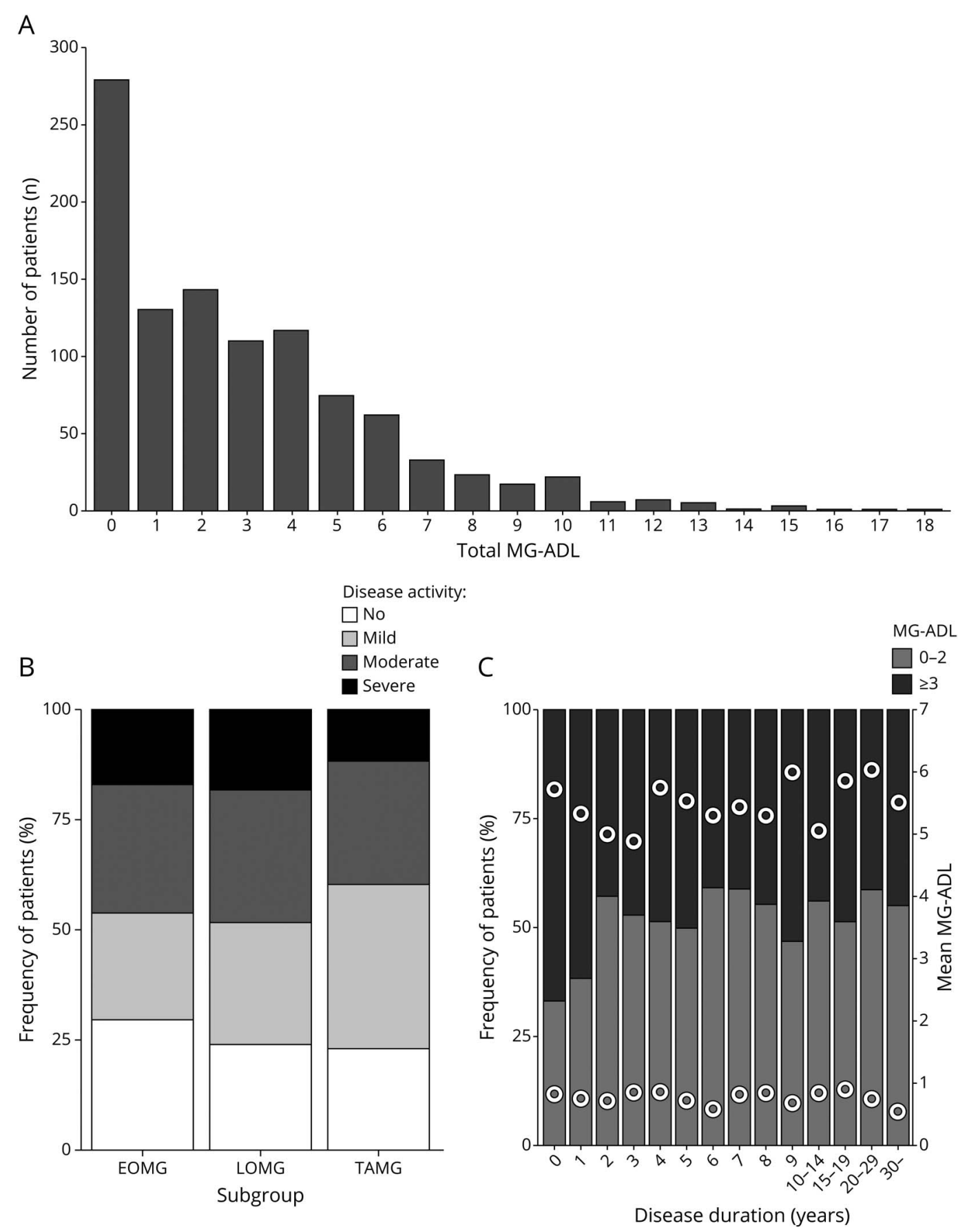

(A) Total MG-ADL for all patients submitting complete MG-ADL scores $(n=1,035)$. (B) Distribution of MG-ADL score divided into no (0p), mild $(1 p-2 p)$, and moderate disease activity ( $3 p-5 p$ and patients with $6 p$ limited to ocular items) as well as severe generalized disease ( $\geq 6 p$ of which at least $1 p$ is in nonocular items) per subgroup. (C) Distribution of estimated patient acceptable symptom state (PASS) determined by an MG-ADL cutoff at Op-2p and $\geq 3 p$ by disease duration. Mean MG-ADL within each category is displayed as filled dots. Data shown for all patients with complete MG-ADL scores and disease duration ( $\mathrm{n}=$ 1,026). EOMG = early-onset myasthenia gravis; LOMG = late-onset myasthenia gravis; TAMG = thymoma-associated myasthenia gravis.

doses of choline esterase inhibitors or immunomodulatory agents. To provide more precise information on this matter, a study linking the GEMG database with the national prescribed drugs registry is being planned.

We describe characteristics correlating with disease activity in a nationwide prevalence MG cohort covering $42 \%$ of the total patient population in Sweden. We show that women and patients with obesity are at higher risk of reporting residual symptoms. Furthermore, almost half of the study population potentially reported an unsatisfactory disease state, highlighting the need for developing improved therapeutic interventions for this condition. 
Table 3 Factors Influencing Risk of Severe Generalized Disease

\begin{tabular}{llll}
\hline & OR & $95 \% \mathrm{Cl}$ & $\boldsymbol{p}$ Value \\
\hline Female sex & 1.62 & $1.09,2.41$ & $0.017^{\mathrm{a}}$ \\
\hline Subgroup & & & \\
\hline LOMG & 1.47 & $0.70,3.09$ & 0.3 \\
\hline Thymoma & 0.82 & $0.26,2.16$ & 0.7 \\
\hline University degree & 0.59 & $0.37,0.91$ & $0.020^{\mathrm{a}}$ \\
\hline Current tobacco & 0.90 & $0.54,1.45$ & 0.7 \\
\hline Body mass index & & & \\
\hline Overweight & 1.03 & $0.68,1.57$ & 0.9 \\
\hline Obesity & 1.72 & $1.12,2.64$ & $0.013^{\mathrm{a}}$ \\
\hline Diagnostic delay $\geq \mathbf{2} \mathbf{y}$ & 1.69 & $1.14,2.48$ & $0.008^{\mathrm{a}}$ \\
\hline Disease duration, $\mathbf{y}$ & 1.00 & $0.98,1.02$ & $>0.9$ \\
\hline Age at inclusion, $\mathbf{y}$ & 1.00 & $0.98,1.01$ & 0.6 \\
\hline
\end{tabular}

Abbreviations: $\mathrm{Cl}$ = confidence interval; LOMG = late-onset myasthenia gravis; $\mathrm{OR}=$ odds ratio.

Comparison of severe generalized disease, defined as myasthenia gravis activities of daily living (MG-ADL) $6 p$ or higher with at least $1 p$ from nonocular items, and the absence thereof, defined as MG-ADL below $6 \mathrm{p}$ or only ocular symptoms. Disease duration is calculated from year of onset. OR and $p$ values adjusted for all included variables.

${ }^{a}$ Significant.

\section{Study Funding}

The study was supported by the Swedish medical association, Karolinska Institutet research funds, Åke Wiberg Foundation, and Tore Nilsson Foundation.

\section{Disclosure}

M. Petersson, A. Feresiadou, D. Jons, A. Ilinca, F. Lundin, R. Johansson, A. Budzianowska, A.-K. Roos, V. Kågström, M. Gunnarsson, and P. Sundström report no disclosures relevant to the manuscript. F. Piehl has received an unrestricted research grant from UCB Pharma. S. Brauner reports no disclosures relevant to the manuscript. Go to Neurology.org/N for full disclosures.

\section{Publication History}

Received by Neurology March 3, 2021. Accepted in final form July 9, 2021.

\section{Appendix Authors}

\begin{tabular}{lll}
\hline Name & Location & Contribution \\
\hline $\begin{array}{l}\text { Malin } \\
\text { Petersson, MD }\end{array}$ & $\begin{array}{l}\text { Karolinska Institutet, } \\
\text { Stockholm, Sweden }\end{array}$ & $\begin{array}{l}\text { Analyzed data, drafted and } \\
\text { revised manuscript }\end{array}$ \\
\hline $\begin{array}{l}\text { Amalia } \\
\text { Feresiadou, MD }\end{array}$ & $\begin{array}{l}\text { Uppsala University Hospital } \\
\text { and Uppsala University, } \\
\text { Sweden }\end{array}$ & $\begin{array}{l}\text { Acquisition of data, revised } \\
\text { manuscript }\end{array}$ \\
\hline Daniel Jons, MD & $\begin{array}{l}\text { Sahlgrenska University } \\
\text { Hospital and University of } \\
\text { Gothenburg, Sweden }\end{array}$ & $\begin{array}{l}\text { Acquisition of data, revised } \\
\text { manuscript }\end{array}$ \\
\hline & & \\
\hline
\end{tabular}

Appendix (continued)

\begin{tabular}{|c|c|c|}
\hline Name & Location & Contribution \\
\hline $\begin{array}{l}\text { Andrea llinca, } \\
\text { MD, PhD }\end{array}$ & $\begin{array}{l}\text { Skåne University Hospital } \\
\text { and Lund University, } \\
\text { Malmö, Sweden }\end{array}$ & $\begin{array}{l}\text { Acquisition of data, revised } \\
\text { manuscript }\end{array}$ \\
\hline $\begin{array}{l}\text { Fredrik Lundin, } \\
\text { MD, PhD }\end{array}$ & $\begin{array}{l}\text { Linköping University } \\
\text { Hospital and Linköping } \\
\text { University, Sweden }\end{array}$ & $\begin{array}{l}\text { Acquisition of data, revised } \\
\text { manuscript }\end{array}$ \\
\hline $\begin{array}{l}\text { Rune } \\
\text { Johansson, MD }\end{array}$ & $\begin{array}{l}\text { Karlstad Central Hospital, } \\
\text { Sweden }\end{array}$ & $\begin{array}{l}\text { Acquisition of data, revised } \\
\text { manuscript }\end{array}$ \\
\hline $\begin{array}{l}\text { Anna } \\
\text { Budzianowska, } \\
\text { MD }\end{array}$ & $\begin{array}{l}\text { Ryhov Hospital, Jönköping, } \\
\text { and Linköping University, } \\
\text { Sweden }\end{array}$ & $\begin{array}{l}\text { Acquisition of data, revised } \\
\text { manuscript }\end{array}$ \\
\hline $\begin{array}{l}\text { Anna-Karin } \\
\text { Roos, MD }\end{array}$ & $\begin{array}{l}\text { Östersund Hospital and } \\
\text { Umeå University, Sweden }\end{array}$ & $\begin{array}{l}\text { Acquisition of data, revised } \\
\text { manuscript }\end{array}$ \\
\hline $\begin{array}{l}\text { Viktor } \\
\text { Kågström, MD }\end{array}$ & Sundsvall Hospital, Sweden & $\begin{array}{l}\text { Acquisition of data, revised } \\
\text { manuscript }\end{array}$ \\
\hline $\begin{array}{l}\text { Martin } \\
\text { Gunnarsson, } \\
\text { MD, PhD }\end{array}$ & $\begin{array}{l}\text { Örebro University Hospital } \\
\text { and Örebro University, } \\
\text { Sweden }\end{array}$ & $\begin{array}{l}\text { Acquisition of data, revised } \\
\text { manuscript }\end{array}$ \\
\hline $\begin{array}{l}\text { Peter } \\
\text { Sundström, } \\
\text { MD, PhD }\end{array}$ & $\begin{array}{l}\text { University Hospital of Umeå } \\
\text { and Umeå University, } \\
\text { Sweden }\end{array}$ & $\begin{array}{l}\text { Acquisition of data, revised } \\
\text { manuscript }\end{array}$ \\
\hline $\begin{array}{l}\text { Fredrik Piehl, } \\
\text { MD, PhD }\end{array}$ & $\begin{array}{l}\text { Karolinska University } \\
\text { Hospital and Karolinska } \\
\text { Institutet, Stockholm, } \\
\text { Sweden }\end{array}$ & $\begin{array}{l}\text { Designed and } \\
\text { conceptualized study, } \\
\text { acquisition of data, } \\
\text { interpreted data and } \\
\text { revised manuscript }\end{array}$ \\
\hline $\begin{array}{l}\text { Susanna } \\
\text { Brauner, MD, } \\
\text { PhD }\end{array}$ & $\begin{array}{l}\text { Karolinska University } \\
\text { Hospital and Karolinska } \\
\text { Institutet, Stockholm, } \\
\text { Sweden }\end{array}$ & $\begin{array}{l}\text { Designed and } \\
\text { conceptualized study, } \\
\text { acquisition of data, } \\
\text { interpreted data and } \\
\text { revised manuscript }\end{array}$ \\
\hline
\end{tabular}

\section{References}

1. Gilhus NE, Tzartos S, Evoli A, Palace J, Burns TM, Verschuuren J. Myasthenia gravis. Nat Rev Dis Primers. 2019;5(1):30.

2. Gilhus NE, Skeie GO, Romi F, Lazaridis K, Zisimopoulou P, Tzartos S. Myasthenia gravis: autoantibody characteristics and their implications for therapy. Nat Rev Neurol. 2016;12(5):259-268

3. Grob D, Brunner N, Namba T, Pagala M. Lifetime course of myasthenia gravis. Muscle Nerve. 2008;37(2):141-149.

4. Jones SM, Gwathmey KG, Burns TM. Quality of life measures for myasthenia gravis and evaluation of non-motor symptoms. Clin Exp Neuroimmunol. 2015;6(1):32-39.

5. Nelson EC, Eftimovska E, Lind C, Hager A, Wasson JH, Lindblad S. Patient reported outcome measures in practice. BMJ. 2015;350:g7818.

6. Wolfe GI, Herbelin L, Nations SP, Foster B, Bryan WW, Barohn RJ. Myasthenia gravis activities of daily living profile. Neurology. 1999;52(7):1487-1489.

7. Barnett C, Herbelin L, Dimachkie MM, Barohn RJ. Measuring clinical treatment response in myasthenia gravis. Neurol Clin. 2018;36(2):339-353.

8. Muppidi S, Wolfe GI, Conaway M, Burns TM, Mg C; MG-QOL15 Study Group. MG-ADL: still a relevant outcome measure. Muscle Nerve. 2011;44(5):727-731.

9. Mendoza M, Tran C, Bril V, Katzberg HD, Barnett C. Patient-acceptable symptom states in myasthenia gravis. Neurology. 2020;95(12):e1617-e1628.

10. Howard JF Jr, Utsugisawa K, Benatar M, et al. Safety and efficacy of eculizumab in anti-acetylcholine receptor antibody-positive refractory generalised myasthenia gravis (REGAIN): a phase 3, randomised, double-blind, placebo-controlled, multicentre study. Lancet Neurol. 2017;16(12):976-986.

11. Vissing J, O'Brien F, Wang JJ, Howard JF Jr. Correlation between myasthenia gravis-activities of daily living (MG-ADL) and quantitative myasthenia gravis (QMG) assessments of anti-acetylcholine receptor antibody-positive refractory generalized myasthenia gravis in the phase 3 regain study. Muscle Nerve. 2018; 58(2):E21-E22.

12. Howard JF Jr, Freimer M, O’Brien F, et al. QMG and MG-ADL correlations: study of eculizumab treatment of myasthenia gravis. Muscle Nerve. 2017;56(2):328-330.

13. Fang F, Sveinsson O, Thormar G, et al. The autoimmune spectrum of myasthenia gravis: a Swedish population-based study. J Intern Med. 2015;277(5):594-604. 
14. Westerberg E, Punga AR. Epidemiology of myasthenia gravis in Sweden 2006-2016. Brain Behav. 2020:e1819.

15. Carr AS, Cardwell CR, McCarron PO, McConville J. A systematic review of population based epidemiological studies in Myasthenia Gravis. BMC Neurol. 2010;10:46

16. Kalb B, Matell G, Pirskanen R, Lambe M. Epidemiology of myasthenia gravis: a population-based study in Stockholm, Sweden. Neuroepidemiology. 2002;21(5): 221-225.

17. Murai H, Yamashita N, Watanabe M, et al. Characteristics of myasthenia gravis according to onset-age: Japanese nationwide survey. J Neurol Sci. 2011;305(1-2): 97-102.

18. Suzuki S, Utsugisawa K, Nagane Y, Satoh T, Kuwana M, Suzuki N. Clinical and immunological differences between early and late-onset myasthenia gravis in Japan. J Neuroimmunol. 2011;230(1-2):148-152.

19. Hedstrom AK, Hillert J, Olsson T, Alfredsson L. Alcohol as a modifiable lifestyle factor affecting multiple sclerosis risk. JAMA Neurol. 2014;71(3):300-305.

20. Hedstrom AK, Stawiarz L, Klareskog L, Alfredsson L. Smoking and susceptibility to rheumatoid arthritis in a Swedish population-based case-control study. Eur J Epidemiol. 2018;33(4):415-423.

21. Klareskog L, Stolt P, Lundberg K, et al. A new model for an etiology of rheumatoid arthritis: smoking may trigger HLA-DR (shared epitope)-restricted immune reactions to autoantigens modified by citrullination. Arthritis Rheum. 2006;54(1):38-46.

22. Salaffi F, Carotti M, Gutierrez M, Di Carlo M, De Angelis R. Patient acceptable symptom state in self-report questionnaires and composite clinical disease index for assessing rheumatoid arthritis activity: identification of cut-off points for routine care. Biomed Res Int. 2015;2015:930756.

23. Conti F, Ceccarelli F, Massaro L, et al. Evaluation of the patient acceptable symptom state (PASS) in Italian patients affected by systemic lupus erythematosus: association with disease activity indices. PLoS One. 2013;8(9):e73517.

24. R: A Language Environment for Statistical Computing [computer program]. R Foundation for Statistical Computing; 2020.

25. McHugh ML. Interrater reliability: the kappa statistic. Biochem Med. 2012;22(3): 276-282.
26. Koo TK, Li MY. A guideline of selecting and reporting intraclass correlation coefficients for reliability research. J Chiropr Med. 2016;15(2):155-163.

27. Population in the Country, Counties and Municipalities on December 31, 2019 and Population Change in October-December 2019. 2020. scb.se/en/finding-statistics/ statistics-by-subject-area/population/population-composition/population-statistics/ pong/tables-and-graphs/quarterly-population-statistics-municipalities-counties-andthe-whole-country/quarter-4-2019/

28. Barnett AG, van der Pols JC, Dobson AJ. Regression to the mean: what it is and how to deal with it. Int J Epidemiol. 2005;34(1):215-220.

29. Abuzinadah AR, Alanazy MH, Butt NS, Barohn RJ, Dimachkie MM. Exacerbation rate in generalized myasthenia gravis and its predictors. Eur Neurol. 2020:1-6.

30. Dong D, Chong MK, Wu Y, et al. Gender differences in quality of life among patients with myasthenia gravis in China. Health Qual Life Outcomes. 2020;18(1):296.

31. Maniaol AH, Boldingh M, Brunborg C, Harbo HF, Tallaksen CM. Smoking and socioeconomic status may affect myasthenia gravis. Eur J Neurol. 2013;20(3):453-460.

32. Kupersmith MJ, Latkany R, Homel P. Development of generalized disease at 2 years in patients with ocular myasthenia gravis. Arch Neurol. 2003;60(2):243-248.

33. Cortés-Vicente E, Álvarez-Velasco R, Segovia S, et al. Clinical and therapeutic features of myasthenia gravis in adults based on age at onset. Neurology. 2020;94(11): e1171-e1180.

34. Boldingh MI, Maniaol AH, Brunborg C, Weedon-Fekjaer H, Verschuuren JJ, Tallaksen CM. Increased risk for clinical onset of myasthenia gravis during the postpartum period. Neurology. 2016;87(20):2139-2145.

35. Gilhus NE, Verschuuren JJ. Myasthenia gravis: subgroup classification and therapeutic strategies. Lancet Neurol. 2015;14(10):1023-1036.

36. Verwijst J, Westerberg E, Punga AR. Cancer in myasthenia gravis subtypes in relation to immunosuppressive treatment and acetylcholine receptor antibodies: a Swedish nationwide register study. Eur J Neurol. 2021;28:1706-1715.

37. Cutter G, Xin H, Aban I, et al. Cross-sectional analysis of the myasthenia gravis patient registry: disability and treatment. Muscle Nerve. 2019;60(6):707-715.

38. Barnett C, Bril V, Kapral M, Kulkarni A, Davis AM. Development and validation of the myasthenia gravis impairment index. Neurology. 2016;87(9):879-886. 


\section{Neurology}

\section{Patient-Reported Symptom Severity in a Nationwide Myasthenia Gravis Cohort: Cross-sectional Analysis of the Swedish GEMG Study \\ Malin Petersson, Amalia Feresiadou, Daniel Jons, et al.}

Neurology 2021;97;e1382-e1391 Published Online before print August 10, 2021

DOI 10.1212/WNL.0000000000012604

This information is current as of August 10, 2021

\section{Updated Information \& Services}

References

Citations

Subspecialty Collections

Errata

Permissions \& Licensing

Reprints including high resolution figures, can be found at: http://n.neurology.org/content/97/14/e1382.full

This article cites 34 articles, 6 of which you can access for free at: http://n.neurology.org/content/97/14/e1382.full\#ref-list-1

This article has been cited by 1 HighWire-hosted articles: http://n.neurology.org/content/97/14/e1382.full\#\#otherarticles

This article, along with others on similar topics, appears in the following collection(s):

\section{Cohort studies}

http://n.neurology.org/cgi/collection/cohort_studies Myasthenia

http://n.neurology.org/cgi/collection/myasthenia

An erratum has been published regarding this article. Please see next page or:

/content/97/24/1141.2.full.pdf

Information about reproducing this article in parts (figures,tables) or in its entirety can be found online at:

http://www.neurology.org/about/about_the_journal\#permissions

Information about ordering reprints can be found online:

http://n.neurology.org/subscribers/advertise

Neurology ${ }^{\circledR}$ is the official journal of the American Academy of Neurology. Published continuously since 1951, it is now a weekly with 48 issues per year. Copyright Copyright ( 2021 The Author(s). Published by Wolters Kluwer Health, Inc. on behalf of the American Academy of Neurology.. All rights reserved. Print ISSN: 0028-3878. Online ISSN: 1526-632X.

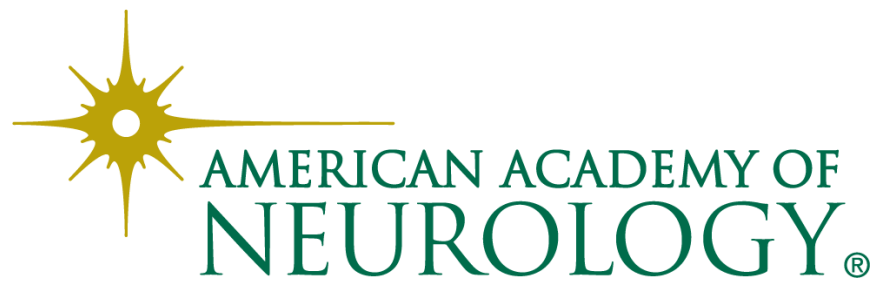




\section{Disputes \& Debates: Editors' Choice}

Steven Galetta, MD, FAAN, Editor

Aravind Ganesh, MD, DPhil, FRCPC, Deputy Editor

Ariane Lewis, MD, Deputy Editor

James E. Siegler III, MD, Deputy Editor

\section{Editors' Note: Automated Quantitative Pupillometry in the Critically III:} A Systematic Review of the Literature

In "Automated Quantitative Pupillometry in the Critically Ill: A Systematic Review of the Literature," Opic et al. summarized 58 articles (10 randomized trials) published from 1990 to 2019 on the use of automated pupillometry in adult critically ill patients. They reported that increased intracranial pressure (ICP), traumatic brain injury (TBI), ischemic brain damage, opioids and hypoxemia, and hypercarbia are potential confounders for pupillometry. Taccone et al. commented that increased ICP, TBI, and hypoxic ischemic brain injury (HIBI) should not be considered confounders of pupillometry (circumstances in which the test may be unreliable) but rather injuries that can cause pupillary abnormalities and that altered pupillary responses in these settings could be indicative of poor prognosis. In response, Opic et al. reinforced that medications can confound the pupillary assessment in certain circumstances but did not address the distinction between whether increased ICP, TBI, and HIBI typically confound or cause pupillary abnormalities. Larson commented that although opioids cause pupillary constriction, they do not affect the strength of the pupillary light reflex (PLR). They also pointed out that the systematic review did not include an article by Rollins et al., which described the persistence of a robust quantifiable PLR in the setting of opioid-induced hypoxia and hypercarbia. Opic et al. noted that they eliminated some articles based on the exclusion criteria of studies that used nonhandheld devices, but it is worth noting that Rollins et al. did, in fact, use a handheld device (the Neuroptics ForSite). ${ }^{1,2}$ Opic et al. acknowledged that although the PLR involves both static and dynamic parameters, most of the studies they reviewed regarding the impact of opioids on pupillometry discussed their confounding impact on static parameters. Opic et al. and Larson reinforced that pupillometry always requires interpretation by a clinician based on an individual patient's circumstances.

Ariane Lewis, MD, and Steven Galetta, MD

Neurology ${ }^{\circledR}$ 2021;97:1138. doi:10.1212/WNL.0000000000012979

1. Rollins M, Feiner J, Lee J, Shah S, Larson M. Pupillary effects of high-dose opioid quantified with infrared pupillometry. Anesthesiology. 2014;121(5):1037-1044.

2. Du R, Meeker M, Bacchetti P, Larson M, Holland M, Manley G. Evaluation of the portable infrared pupillometer. Neurosurgery. 2005; 57(1):198-202.

\section{Reader Response: Automated Quantitative Pupillometry in the Critically Ill: A Systematic Review of the Literature}

Fabio S. Taccone (Brussels) and Giuseppe Citerio (Monza, Italy)

Neurology ${ }^{\circledR}$ 2021;97:1138-1139. doi:10.1212/WNL.0000000000012981

We read with interest the systematic review by Opic et al., ${ }^{1}$ which addressed the presence of potential confounders for outcome prediction in critically ill patients with automated pupillometry. Standard pupil variables such as size and constriction velocity were considered together 
with the Neurologic Pupil Index (NPI), which is not influenced by medications or the environment. $^{2}$

In addition, the clinical scenario after cardiac arrest is misleading. Extended hypoxic brain damage or increased intracranial pressure (ICP) would not be a confounder for pupillary assessment, even with the inclusion of the NPI criteria. These phenomena are the mechanisms inducing pupillary alterations in patients and the reason why clinicians monitor pupillary size and reactivity in this setting. Of course, sedatives or analgesics can influence pupillary metrics. However, NPI has been shown to be a predictive of poor outcomes in this setting, without false positives, within 24 hours after cardiac arrest. ${ }^{3}$

The same comment could be applied for traumatic brain injury (TBI). The presence of elevated ICP and brainstem compression may be the cause of pupillary dysfunction, rather than a confounder. Pupillary alterations are well-known predictors of poor outcomes after severe TBI and useful clinical monitoring tools in these patients.

1. Opic P, Rüegg S, Marsch S, Gut SS, Sutter R. Automated quantitative pupillometry in the critically ill: a systematic review of the literature. Neurology. 2021;97(6):e629-e642.

2. Shirozu K, Setoguchi H, Tokuda K, et al. The effects of anesthetic agents on pupillary function during general anesthesia using the automated infrared quantitative pupillometer. J Clin Monit Comput. 2017;31(2):291-296.

3. Oddo M, Sandroni C, Citerio G, et al. Quantitative versus standard pupillary light reflex for early prognostication in comatose cardiac arrest patients: an international prospective multicenter double-blinded study. Intensive Care Med. 2018;44(12):2102-2111.

Copyright (c) 2021 American Academy of Neurology

\section{Author Response: Automated Quantitative Pupillometry in the Critically Ill: A Systematic Review of the Literature}

Petra Opic (Basel, Switzerland) and Raoul Sutter (Basel, Switzerland)

Neurology ${ }^{\circledR}$ 2021;97:1139. doi:10.1212/WNL.0000000000012983

We thank the commenters for their valuable input on our study. ${ }^{1}$ We consider it impossible to evaluate a patient for increased cranial pressure (ICP) using pupillometry without taking the patients' clinical context into account. ${ }^{1}$ One of the items considered in clinical context is the use of medications that would alter pupillary reactions to exclude potentially false-negative or falsepositive pupillometric results.

Patients with ICP often receive a wide range of concomitant medications. In this context, it is important to consider whether abnormal pupillary reactions reflect changes in intracranial pressure or are the result of concomitant medications (eg, ipratropium). ${ }^{2,3}$ In other words, is there a factor present that causes a false-negative or false-positive pupillometric result?

The potential confounders listed in our review have all been shown to influence pupils to some degree and can be present at the same time during pupillary evaluation. When evaluating for one factor that could alter pupillary dynamics, concurrent influences from other potential confounding factors need to be excluded to avoid potential false-negative or false-positive results.

1. Opic P, Rüegg S, Marsch S, Gut SS, Sutter R. Automated quantitative pupillometry in the critically ill: a systematic review of the literature. Neurology. 2021;97(6):e629-e642.

2. Singhal NS, Josephson SA. A practical approach to neurologic evaluation in the intensive care unit. J Crit Care. 2014;29(4):627-633.

3. Kokulu K, Öner H, Özen C, Eroğlu SE, Altunok İ, Akça HŞ. Pharmacologic anisocoria due to nebulized ipratropium bromide: a diagnostic challenge. Am J Emerg Med. 2019;37(6):1217.e3-1217.e4.

4. Chaudhry P, Friedman DI, Yu W. Unilateral pupillary mydriasis from nebulized ipratropium bromide: a false sign of brain herniation in the intensive care unit. Indian J Crit Care Med. 2014;18(3):176-177.

Copyright (c) 2021 American Academy of Neurology

Author disclosures are available upon request (journal@neurology.org). 


\section{Reader Response: Automated Quantitative Pupillometry in the Critically Ill: A Systematic Review of the Literature}

Merlin D. Larson (San Francisco)

Neurology ${ }^{\circledR}$ 2021;97:1140. doi:10.1212/WNL.0000000000012982

Opic et al. are to be commended for listing the various factors that can affect the pupillary light reflex (PLR). ${ }^{1}$ The PLR is like any other medical test because it requires interpretation by a physician who considers the result in the light of other information about the patient to determine a diagnosis and treatment. If the PLR has any value at all, then it seems preferable to get an objective measurement that can be time-stamped and trended over time.

I am concerned as to why the authors list opioids as a confounding factor. It is commonly known that opioids constrict the pupil, but the authors state that the article is focused on the PLR. Opioids do not alter the PLR, when measured by a parameter that is independent to the size of the pupil. Two important references that emphasize this point are missing in the article. ${ }^{2,3}$ One relevant reference is included, but the point regarding the PRL is not commented on. ${ }^{4}$ The Neurological Pupil Index (NPI) provides a measurement of the strength of the light reflex that is independent from pupil size and would not be altered by toxic doses of opioids.

1. Opic P, Rüegg S, Marsch S, Gut SS, Sutter R. Automated quantitative pupillometry in the critically Ill: a systematic review of the literature. Neurology. 2021;97(6):e629-e642.

2. Daniel M, Larson MD, Eger EI II, Noorani M, Weiskopf RB. Fentanyl, clonidine, and repeated increases in desflurane concentration, but not nitrous oxide or esmolol, block the transient mydriasis caused by rapid increases in desflurane concentration. Anesth Analg. 1995; 81(2):372-378.

3. Rollins MD, Feiner JR, Lee JM, Shah S, Larson M. Pupillary effects of high-dose opioid quantified with infrared pupillometry. Anesthesiology. 2014;121(5):1037-1044.

4. Larson MD, Kurz A, Sessler DI, Dechert M, Bjorksten AR, Tayefeh F. Alfentanil blocks reflex pupillary dilation in response to noxious stimulation but does not diminish the light reflex. Anesthesiology. 1997;87(4):849-855.

\section{Author Response: Automated Quantitative Pupillometry in the Critically Ill: A Systematic Review of the Literature}

Petra Opic (Basel, Switzerland) and Raoul Sutter (Basel, Switzerland)

Neurology ${ }^{\circledR}$ 2021;97:1140-1141. doi:10.1212/WNL.0000000000012984

We thank the reader for the interest in our study and the kind remarks. ${ }^{1}$ Indeed, we consider the pupillary light reflex (PLR) a medical test that should be interpreted in light of a clinical context. Moreover, pupillometry has the advantage of being objective and allows for standardized assessment over time.

We were not able to include all suggested articles in the study because of our exclusion criteria concerning handhelds. Most of the studies involving opioids focused solely on static parameters. We showed a clear paucity of data regarding opioid dynamic pupillary parameters, and therefore, firm conclusions could not be drawn.

In addition, the article mentioned by the author investigated patients during hypoxemia and hypercarbia without mechanical ventilation. ${ }^{2}$ The sympathetic drive caused by hypoxemia and hypercarbia can influence pupillary reactions and could potentially be counteracted by the mechanical ventilation ICU patients often receive. Moreover, a maximal miosis could be triggered with very high doses of opioids. ${ }^{3,4}$ During maximal miosis with no possibility of further contraction, it remains unclear how any further pupillary contraction can be seen. 
Finally, we recognize the term PLR tends to be ambiguous. In the context of our article, both static and dynamic parameters are considered in figure 4.

1. Opic P, Rüegg S, Marsch S, Gut SS, Sutter R. Automated quantitative pupillometry in the critically ill: a systematic review of the literature. Neurology. 2021;97(6):e629-e642.

2. Rollins MD, Feiner JR, Lee JM, Shah S, Larson M. Pupillary effects of high-dose opioid quantified with infrared pupillometry. Anesthesiology. 2014;121(5):1037-1044.

3. Parthvi R, Agrawal A, Khanijo S, Tsegaye A, Talwar A. Acute opiate overdose: an update on management strategies in emergency department and critical care unit. Am J Ther. 2019;26(3):e380-e387.

4. Fliegert F, Kurth B, Göhler K. The effects of tramadol on static and dynamic pupillometry in healthy subjects-the relationship between pharmacodynamics, pharmacokinetics and CYP2D6 metaboliser status. Eur J Clin Pharmacol. 2005;61(4):257-266.

Copyright @ 2021 American Academy of Neurology

CORRECTIONS

\section{Geriatric Syndromes and Treatment Toxicities in Older Patients With Malignant Gliomas (4327)}

Neurology ${ }^{\circledR}$ 2021;97:1141. doi:10.1212/WNL.0000000000013032

In the American Academy of Neurology annual meeting abstract "Geriatric Syndromes and Treatment Toxicities in Older Patients With Malignant Gliomas (4327)” by Alam et al., the first sentence of the Disclosure should read "Mr. Alam has nothing to disclose." The authors regret the error.

\section{Reference}

1. Alam A, Wasilewski A, Mohile N. Geriatric syndromes and treatment toxicities in older patients with malignant gliomas (4327). Neurology. 2020;94(15 suppl):4327.

\section{Patient-Reported Symptom Severity in a Nationwide Myasthenia Gravis Cohort} Cross-sectional Analysis of the Swedish GEMG Study Neurology ${ }^{\circledR}$ 2021;97:1141. doi:10.1212/WNL.0000000000013021

In the Research Article "Patient-Reported Symptom Severity in a Nationwide Myasthenia Gravis Cohort: Cross-sectional Analysis of the Swedish GEMG Study" by Petersson et al., the third sentence of the third paragraph of the Results should read: "Using a multivariate regression model, comparing patients with severe generalized disease to those without, we sought to identify factors correlating with higher MG-ADL score (Table 3).” The publisher regrets the error.

\section{Reference}

1. Petersson M, Feresiadou A, Jons D, et al. Patient-reported symptom severity in a nationwide myasthenia gravis cohort: cross-sectional analysis of the Swedish GEMG Study. Neurology. 2021;97(14):e1382-e1391. 